International Research Journal of Science and Technology Vol. 1, Issue. 2 (2020), 100-105

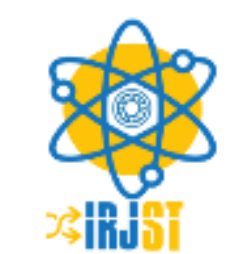

Available online at https://www.irjst.com/

International Research Journal of Science and Technology

ISSN:2707-3955

DOI: https://doi.org/10.46378/irjst.2020.010205

\title{
Seroprevalence of Major Transfusion-Transmissible Infections among Foreign Departing Employees from Itahari, Nepal.
}

\author{
Jenish Shakya $^{1}$, Bijay Kumar Shrestha ${ }^{2}$ and Hemanta Khanal ${ }^{3}$ \\ ${ }^{1}$ Researcher, ${ }^{2}$ Researcher, ${ }^{3}$ Assistant Professor \\ Department of Microbiology, Central Campus of Technology, Tribhuvan University, Dharan, Nepal
}

\begin{tabular}{lll}
\multicolumn{2}{l}{ Paper Status } & \\
Received & $:$ & January 2020 \\
Accepted & $:$ & March 2020 \\
Published & $:$ & March 2020
\end{tabular}

Key Words

Foreign employment.

$H B V$

$H C V$

$H I V$

Seroprevalence

Syphilis

\begin{abstract}
Transfusion-Transmissible Infections (TTIs) include human immunodeficiency virus (HIV), hepatitis B virus (HBV), hepatitis C virus (HCV) and syphilis that are transmitted from person to person through parenteral, administration of blood or blood products leading to serious health problems. The present study was lab based cross-sectional study conducted from February 2018 to August 2019 to investigate the prevalence of hepatitis $\mathrm{B}, \mathrm{HIV}$, hepatitis $\mathrm{C}$, and syphilis among the foreign departing employees from Itahari, Sunsari, Nepal. The samples were screened for the presence of anti-HIV IgG, HBsAg, anti-syphilis and anti-HCV IgG using commercial rapid test kits following standard protocols. A total of 4260 samples processed, the overall seroprevalence of TTIs was found to be $1.22 \%$ (52/4260). Seroprevalence of HIV was found to be $0.05 \%$ (2/4260), HBV was found to be $0.53 \%$ (23/4260), HCV was found to be $0.18 \%(8 / 4260)$ and syphilis was found to be $0.45 \%$ (19/4260). Among the transfusion transmissible infections in individuals going for foreign employment, the most prevalent was found to be hepatitis B $(0.53 \%)$. In overall, the TTIs infection was most prevalent in the age group of $24-29(0.35 \%)$ and $30-35(0.35 \%)$ years. Further investigation including studying the prevalence of TTIs in general population is required to address the issue and to formulate proper preventive, diagnosis and treatment procedures of these infections.
\end{abstract}

Copyright (C) 2020 : Jenish Shakya, Bijay Kumar Shrestha, Hemanta Khanal.This is an open access distribution, and reproduction in any medium, provided Access article distributed under the Creative Commons Attribution License the original work is properly cited License, which permits unrestricted use.

Citation : Jenish Shakya, Bijay Kumar Shrestha, Hemanta Khanal.. "Seroprevalence of Major Transfusion-Transmissible Infections among Foreign Departing Employees from Itahari, Nepal.”, International Research Journal of Science and Technology, $1(2), 100-105,2020$.

\section{Introduction}

The most common and fatal infections that are transmitted through blood are human immunodeficiency virus (HIV), hepatitis $\mathrm{B}$ virus (HBV), hepatitis $\mathrm{C}$ virus ( $\mathrm{HCV}$ ) and syphilis which are most important agents responsible for transfusion transmissible infections (TTIs) [1]. HBV and HCV infections are one of the major diseases that cause serious public health problem that ultimately leads in fatal condition like liver cancer $[2,3]$.

\footnotetext{
*Corresponding Author: Jenish Shakya.

Department of Microbiology, Central Campus of Technology,

Dharan, Nepal, e-mail: jenish11.js@gmail.com
}

Transmission route of hepatitis include sexual contact, blood transfusion and transfusion with other human blood products, re-use of contaminated needles and syringes and vertical transmission from mother to child during child birth [4]. It has been estimated that, annually, about 1.2 million people die globally from chronic HBV infection [5]. The low prevalence of this infection in Nepal is due to an absence of significant vertical transmission and its predominant spread by horizontal transmission among the adolescent age group [6]. Hepatitis infections in Nepal are among intravenous drug users (IDU) in which a few is caused even by tattooing [7]. 
The epidemiology of HIV/AIDS is closely linked to the process of migration. Migrants-and mobile populations in general have significant role in the initial spread of HIV [8]. Syphilis is a highly contagious disease spread primarily by unsafe sexual contact, including oral and anal sex with infected individual, caused by the bacteria Treponema pallidum [9]. The World Health Organization (WHO) estimates that 12 million new cases of syphilis occur each year and the greatest number of cases was estimated to have occurred in the South and Southeast Asia [10]. Therefore we conducted this study among the individuals departing abroad for employment to find out the seroprevalence of HIV, HCV, HBV and syphilis. This study is aimed not only to provide information on prevalence but also aware the concerned authority in affordable diagnosis, prevention and treatment of TTIs infection before it leads to global burden.

\section{Material and Methods}

\subsection{Study Site and Population}

Present study was a lab based cross sectional study conducted at Tertiary Healthcare Centre, Itahari, from the period of February 2018 to August 2019. Approval was obtained from the administration center before carrying out the research. The study population included foreign going employee who requested for medical checkup before departing abroad. Informed consent was obtained and the information of the individuals such as age, gender was obtained during their visit through questionnaire. The individuals who were unwilling to participate were not included in the study.

The researcher has conducted a serious of literature reviews to assess the major issues and concepts in the field of data mining. Various books, journals, articles and papers from the Internet has been read to assess the importance and applications of data mining technology in general and its application on educational data in particular.

\subsection{Laboratory Testing}

Blood samples were collected by professional laboratory technicians using aseptic techniques. Using a sterile syringe, $5 \mathrm{ml}$ of blood was drawn and dispensed in a small clean test tube labeled with the corresponding sample number. Blood samples collected in small test tubes were centrifuged at 3000 rpm for 4 to 5 minutes to separate serum/plasma required for screening the tests. All serum samples were tested for the presence of anti-HIV, HBsAg, anti$\mathrm{HCV}$ and anti-Treponemal antibodies using the commercially available EIA based kits (Anti-HIV:
HIV Tri-Dot, J Mitra and Co. Pvt. Ltd., India; HbsAg: SD BIOLINE, Syphilis Fast 3.0 Standard Diagnostics, INC, Korea; Syphilis: ABON TM Syphilis, ultra-rapid test device, ABON Biopharma CO. Ltd., China; HCV: HCV Tri-Dot, J. Mitra and Co. Pvt. Ltd., India). All the tests were performed following the standard protocols recommended by kit manufacturers maintaining all standard operating procedures.

\subsection{Statistical Analysis}

Data was tabulated in Microsoft excel 2010 and Statistical analysis was done using SPSS version 16.0. The associations between categorical variables were tested using Chi-square test and p-values less than 0.05 were considered to be statistically significant.

\section{Result}

\subsection{Prevalence of TTIs in Study Population}

In the present study the total study population was 4260 out of which $3420(80.28 \%)$ were males and 840 $(19.72 \%)$ were females. The overall prevalence of TTIs infection in this study was found to be 52 $(1.22 \%)$ in 4260 study population.

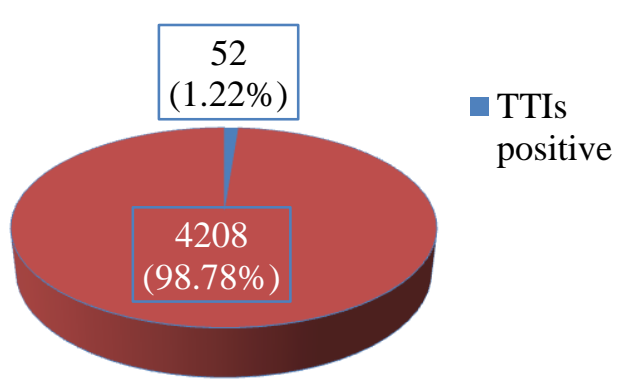

Figure 1. Prevalence of TTIs in study population

\subsection{Prevalence of TTIs infection among study population}

Among the positive cases, the highest prevalence was seen in HBV i.e., $23(0.53 \%)$ followed by Syphilis 19 $(0.45 \%)$, HCV $8(0.18 \%)$ and the least was seen in HIV i.e., $2(0.05 \%)$ which was statistically significant $(\mathrm{p}<0.05)$. (Ref: Figure 2)

\subsection{Distribution of TTIs According to Gender}

Out of 4260 sample, 48 males and 4 females were found to be infected with TTIs. Thus, the overall prevalence of TTIs in males was found to be $1.4 \%$ and $0.47 \%$ in females. There was high prevalence of TTIs infection among male than in female which was statistically significant $(\mathrm{p}<0.05)$. (Ref: Table 1 .) 


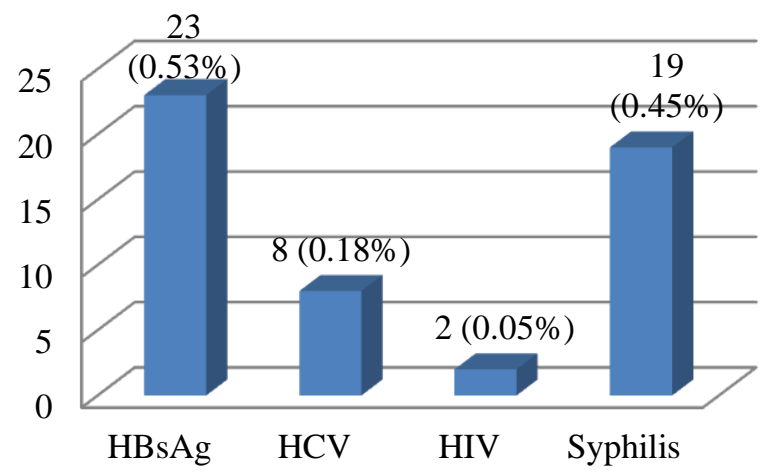

Figure 2. Prevalence of TTIs infections among study population

\subsection{Distribution of TTIs According to Ages}

The prevalence of TTIs was found to be the highest $(0.35 \%)$ in both the age groups of $24-29$ years and 30 35 years and the least $(0.05 \%)$ in the age group 42 and above.(Refer : Figure 3)

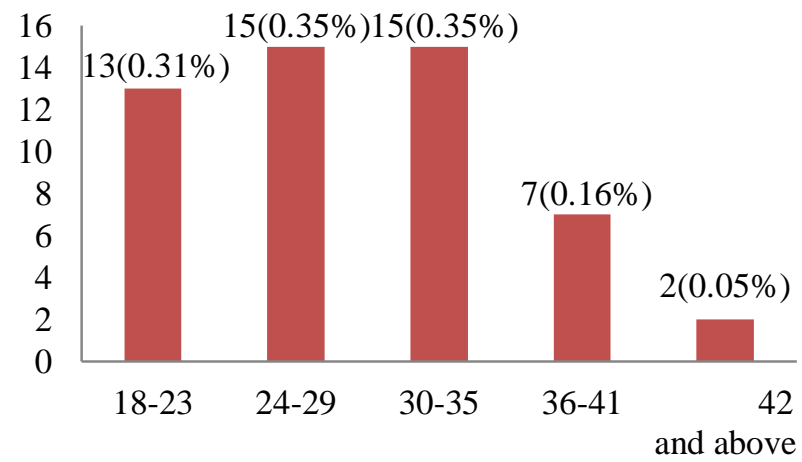

Figure 3. Distribution of TTIs according to ages

\subsection{Distribution of TTIs (HBsAg, HCV, HIV and Syphilis) according to Gender-Ages}

Among males, the highest seroprevalence of HBV, (3.04\%) was observed in the age group 18-23 years followed by $42-45$ years $(1.22 \%)$. In female highest seroprevalence of HBV (10\%) was found in 36-41 age groups.

Among the male individuals, the highest seroprevalence of $\mathrm{HCV},(1.34 \%)$ was observed in the age group 18-23 years followed by 30-35 years age group $(0.34 \%)$ and $36-41$ years age group $(0.34 \%)$. Among females, no positive result was found in any age group.

Among males, the highest seroprevalence of HIV, $(0.08 \%)$ was observed in the age group 30-35 years $(0.08 \%)$ followed by $24-29$ years $(0.07 \%)$. No seroprevalence was observed in other age groups.

Among females, no positive result was found in any age group. Among the male individuals, the highest seroprevalence of syphilis (1.36\%) was observed in the age group 36-41 years followed by $42-45$ years age group (1.22\%). Among females, positive result $(0.42 \%)$ was found only in the age group 24-29 years. (Refer : Table 2).

\section{Discussion}

Nepal is one of the largest suppliers of labor to foreign countries [11]. It is therefore extremely important for screening foreign going employees as these infections raise serious health issues. A majority of known cases of post transfusion diseases have been caused by Human Immunodeficiency Virus (HIV), hepatitis B virus (HBV), hepatitis $\mathrm{C}$ virus (HCV) and syphilis which are indeed a level of concern because these have stood as major health issues of Nepal. In developing nations these infections are behind greater morbidity and mortality among potential risk groups; sex workers, drug addict etc. [12, 13].

In this study out of 4260 total sample screened, the overall prevalence of TTIs was found to be 52 $(1.22 \%)$. Previous studies done among blood donors in various cities of India has reported similar prevalence of TTIs, $1.52 \%$ in Mysuru, India, $1.34 \%$ in Gujarat, $1.35 \%$ in South India which are consistent with this study $[14,15,16]$.

The overall seroprevalence of HBV among foreign going employee was found to be $0.54 \%$. In another study done by Arshad et al (2016) in Pakistan among the blood donors it was found to be $1.84 \%$ [17]. Also the study done by Datta (2008) in Eastern India the prevalence rate was found to be $2-8 \%$ [18] .The study reported $0.64 \%$ seroprevalence of HBV from Andra Pradesh, India, which is consistent with this study [19]. The overall seroprevalence of $\mathrm{HCV}$ among foreign going employee was found to be $0.19 \%$. In another study done by Arshad et al (2016) in Pakistan among the blood donors it was found to be $1.7 \%$ [17]. Similarly in Mysuru, Gujarat, seroprevalence of HCV was $0.15 \%$ which is consistent with our study [14].

Historically, HBV has been considered the main etiological agent for chronic hepatitis until HBV vaccines were introduced, after which $\mathrm{HCV}$ infection became a new health problem [20]. In Asia, Middle East and Africa hepatitis B virus is considered as major health concern, having strong impact on liver, causing chronic liver disease, liver cirrhosis and hepatocellular carcinoma (HCC) [21]. The number of people exposed to hepatitis $\mathrm{C}$ virus in Nepal is estimated to be about 40000 , of these nearly 75000 have chronic hepatitis $\mathrm{C}$. Chronic hepatitis $\mathrm{C}$ has increased threefold in the country in the last two decades, mainly through the intravenous drug use [22]. 
Table 1. Distribution of TTIs According to Gender

\begin{tabular}{llllllllll}
\hline $\begin{array}{l}\text { Study } \\
\text { Variables } \\
\text { (Gender) }\end{array}$ & HBsAg & & HCV & & HIV & & Syphilis & Total \\
\cline { 2 - 10 } & $\mathrm{R}$ & $\mathrm{NR}$ & $\mathrm{R}$ & $\mathrm{NR}$ & $\mathrm{R}$ & $\mathrm{NR}$ & $\mathrm{R}$ & $\mathrm{NR}$ & \\
\hline \multirow{2}{*}{ Male } & 20 & 3400 & 8 & 3412 & 2 & 3418 & 18 & 3402 & 48 \\
& $(0.58 \%)$ & $(99.42 \%)$ & $(0.23 \%)$ & $(99.77 \%)$ & $(0.06 \%)$ & $(99.04 \%)$ & $(0.53 \%)$ & $(99.47 \%)$ & $(1.4 \%)$ \\
Female & 3 & 837 & 0 & 840 & 0 & 840 & 1 & 839 & 4 \\
& $(0.36 \%)$ & $(99.64 \%)$ & $(0.00 \%)$ & $(100 \%)$ & $(0.00 \%)$ & $(100 \%)$ & $(0.12 \%)$ & $(99.88 \%)$ & $(0.47 \%)$ \\
\hline
\end{tabular}

R-Reactive, NR-Non-Reactive

Table 2. Distribution of TTIs (HBsAg, HCV, HIV and Syphilis) according to Gender-Ages

\begin{tabular}{|c|c|c|c|c|c|c|c|c|}
\hline Age & HBsAg & & $\mathrm{HCV}$ & & HIV & & Syphilis & \\
\hline Years & Male & Female & Male & Female & Male & Female & Male & Female \\
\hline $18-23$ & $\begin{array}{l}9 / 296 \\
(3.04 \%)\end{array}$ & $\begin{array}{l}1 / 485 \\
(0.21 \%)\end{array}$ & $\begin{array}{l}1 / 296 \\
(1.34 \%)\end{array}$ & $\begin{array}{l}0 / 485 \\
(0.00 \%)\end{array}$ & $\begin{array}{l}0 / 296 \\
(0.00 \%)\end{array}$ & $\begin{array}{l}0 / 485 \\
(0.00 \%)\end{array}$ & $\begin{array}{l}2 / 296 \\
(0.68 \%)\end{array}$ & $\begin{array}{l}0 / 485 \\
(0.00 \%)\end{array}$ \\
\hline $24-29$ & $\begin{array}{l}5 / 1492 \\
(0.34 \%)\end{array}$ & $\begin{array}{l}1 / 237 \\
(0.42 \%)\end{array}$ & $\begin{array}{l}2 / 1492 \\
(0.13 \%)\end{array}$ & $\begin{array}{l}0 / 237 \\
(0.00 \%)\end{array}$ & $\begin{array}{l}1 / 1492 \\
(0.07 \%)\end{array}$ & $\begin{array}{l}0 / 237 \\
(0.00 \%)\end{array}$ & $\begin{array}{l}5 / 1492 \\
(0.36 \%)\end{array}$ & $\begin{array}{l}1 / 237 \\
(0.42 \%)\end{array}$ \\
\hline $30-35$ & $\begin{array}{l}4 / 1256 \\
(0.32 \%)\end{array}$ & $\begin{array}{l}0 / 106 \\
(0.00 \%)\end{array}$ & $\begin{array}{l}4 / 1256 \\
(0.34 \%)\end{array}$ & $\begin{array}{l}0 / 106 \\
(0.00 \%)\end{array}$ & $\begin{array}{l}1 / 1256 \\
(0.08 \%)\end{array}$ & $\begin{array}{l}0 / 106 \\
(0.00 \%)\end{array}$ & $\begin{array}{l}6 / 1256 \\
(0.48 \%)\end{array}$ & $\begin{array}{l}0 / 106 \\
(0.00 \%)\end{array}$ \\
\hline $36-41$ & $\begin{array}{l}1 / 294 \\
(0.34 \%)\end{array}$ & $1 / 10(10 \%)$ & $\begin{array}{l}1 / 294 \\
(0.34 \%)\end{array}$ & $\begin{array}{l}0 / 10 \\
(0.00 \%)\end{array}$ & $\begin{array}{l}0 / 294 \\
(0.00 \%)\end{array}$ & $\begin{array}{l}0 / 10 \\
(0.00 \%)\end{array}$ & $\begin{array}{l}4 / 294 \\
(1.36 \%\end{array}$ & $0 / 10(0.00 \%)$ \\
\hline $\begin{array}{l}42 \text { and } \\
\text { above }\end{array}$ & $\begin{array}{l}1 / 82 \\
(1.22 \%)\end{array}$ & $\begin{array}{l}0 / 2 \\
(0.00 \%)\end{array}$ & $\begin{array}{l}0 / 82 \\
(0.00 \%)\end{array}$ & $\begin{array}{l}0 / 2 \\
(0.00 \%)\end{array}$ & $\begin{array}{l}0 / 82 \\
(0.00 \%)\end{array}$ & $\begin{array}{l}0 / 2 \\
(0.00 \%)\end{array}$ & $\begin{array}{l}1 / 82 \\
(1.22 \%)\end{array}$ & $0 / 2(0.00 \%)$ \\
\hline Total & $20(0.58 \%)$ & $3(0.36 \%)$ & $8(0.23 \%)$ & 0 & $2(0.06 \%)$ & 0 & $18(0.52 \%)$ & $1(0.11 \%)$ \\
\hline
\end{tabular}

In our study a total of $2(0.05 \%)$ were HIV positive. The prevalence of anti-HIV was observed only in male individuals. Among males, 30-35 years age group showed high prevalence of anti-HIV than other age groups. This age include sexually active population who are susceptible to HIV infection through unsafe sexual intercourse with infected individuals. A similar study done by Shrestha (2009) among blood donors in Kathmandu showed high prevalence of anti-HIV in the age group of 31-40 years which is consistent with this study [6]. In another study done by Arshad et al (2016) in Pakistan among the blood donors it was found to be $0.04 \%$ prevalence to anti-HIV, Similarly in Gujarat, India study done by Dobariya et al (2016) it was found to be $0.081 \%$ seropositive for HIV $[17,15]$. Both the study had the least prevalence of anti-HIV compared to other TTIs which is similar to this study. A study conducted by Silverman et al (2008) in HIV prevalence among sex-trafficked Nepalese girls and women, $38.0 \%$ tested positive for HIV [23]. Two studies done by Gurubacharya and Gurubacharya, (2004) and Poudel et al (2003) have reported the prevalence of HIV among male migrant returnees from India [24, 25]. Male labor migrants who seek work in Mumbai India have been identified as HIV infected increasing the risk of HIV exposure to other general population [25]. HIV prevalence among adult population in the country is below $1 \%$ [26]. However, unsafe sexual behavior by Nepalese HIV infected person even after HIV diagnosis are seen common which is also the major cause behind the spread of HIV infection [27].

The overall seroprevalence of Treponema pallidum; syphilis among foreign going employee was found to be $0.45 \%$. It was found that the prevalence of syphilis was much more than other TTIs. The overall seroprevalence of specific antibodies against Treponema pallidum in Nepalese blood donor was $0.42 \%$ [28]. In context of Nepal, various studies among the high risk individuals have reported the seroprevalence of syphilis. In Nepal the unsafe sexual intercourse with infected individual and furthermore the HIV infected labor migrants seeking work from India have been identified to spread this infection through unsafe sexual activity [25]. In this study many individuals were identified with asymptomatic infection only after they were screened for the medical test which has been made mandatory before foreign departure. This raises a serious issue in asymptomatic 
and unnoticed carriage of TTIs that increases greater fold of escalating the disease leading to uncontrolled morbidity and mortality.

Early investigation of the prevalence of TTIs among foreign departing employees can spot the carriage of unnoticeable infections even in healthy looking condition. Moreover the foreign going employees for work and study must not possess any harm or risk to others within nation and overseas. Introducing safety measures and appropriate clinical treatment in domestic environment to ensure full recovery must be the fundamental priority.

Majority of the problems is due to the prevalence of asymptomatic carriers in the society, as well as blood donations during the window period of infection [29]. Investigation of TTIs infections help to formulate strong strategies to ensure blood safety. In pursuit of global blood safety, the WHO recommends that all blood should be screened for evidence of infection prior to the release of blood and blood components for clinical use. According to WHO guidelines, the screening of all blood donations should be mandatory for HIV, HBV, HCV and syphilis [30].

\section{Conclusion}

The prevalence of $\mathrm{HBV}$ on foreign departing employee is high compared to syphilis, HCV and HIV and this needs further investigation in general population to address the issue. Finally even though the prevalence of TTIs is low, ensuring blood safety it is suggested to launch immediate programs at local level to provide awareness about safe sexual behaviors and prevention on Drug abuse. Nepal government should provide better preventive, routine TTIs diagnosis and treatment facilities and moreover the individual should strictly follow preventive measures against these infections.

\section{Acknowledgements}

The authors would like to thank Microbiology Department of Central Campus of Technology, Tribhuvan University, Hattisar, Dharan, Nepal for encouraging us for conducting research. We would like to extend sincere thanks to Tertiary Healthcare Centre, Itahari and study participants for their valuable support.

\section{Conflict of Interest}

Authors declare no conflict of interest.

\section{Source of Support}

Self-financed.

\section{References}

[1]. Velati C, Romanò L, Fomiatti L, Baruffi L, Zanetti AR and SIMTI Research Group. Impact of nucleic acid testing for hepatitis B virus, hepatitis $\mathrm{C}$ virus, and human immunodeficiency virus on the safety of blood supply in Italy: a 6-year survey. Transfusion. 2008;48(10), 2205-2213.

[2]. Thio CL Seaberg EC, Skolasky Jr.R, Phair J, Visscher B, Muñoz A and Thomas DL. HIV-1, hepatitis $\mathrm{B}$ virus, and risk of liver-related mortality in the Multicenter Cohort Study (MACS). The Lancet. 2002;360(9349), 19211926.

[3]. Bhagat V, Nudo C, and Mindikoglu A. 'Outcomes of Liver Transplantation in Patients with Cirrhosis Due to Nonalcoholic Steatohepatitis Compared to Alcoholic Liver Disease', LIVER. 2009;309(310), 311.

[4]. World Health Organization. Hepatitis B Fact sheet 2019. 2019.

[5]. Shiferaw Y, Alemu A, Girma A, Getahun A, Kassa A, Gashaw A and Gelaw B. Assessment of knowledge, attitude and risk behaviors towards HIV/AIDS and other sexual transmitted infection among preparatory students of Gondar town, north west Ethiopia. BMC research notes. 2011;4(1), 505.

[6]. Shrestha SM. 'Liver cirrhosis and hepatocellular carcinoma in hepatic vena cava disease, a liver disease caused by obstruction of inferior vena cava', Hepatology international. 2009;3(2), 392-402.

[7]. Kakchapati S, Maharjan M, Rawal BB and Dixit SM. Social determinants and risk behaviors associated with prevalent Hepatitis $\mathrm{C}$ and HIV/HCV co-infection among male injection drug users in Nepal. Archives of Public Health. 2017;75(1), 39

[8]. Brummer D. 'Labour migration and HIV/AIDS in southern Africa', International Organization for Migration Regional Office for Southern Africa. 2002;35 (2) 161.

[9]. Ficarra G and Carlos R. 'Syphilis: the renaissance of an old disease with oral implications', Head and neck pathology. 2009;3(3), 195-206.

[10]. Lawn JE, Cousens S, Zupan J and Lancet Neonatal Survival Steering Team. 4 million neonatal deaths: when? Where? Why? The lancet. 2005;365(9462), 891-900.

[11]. Seddon D, Gurung G and Adhikari J.Foreign labour migration and the remittance economy 
of Nepal. HIMALAYA, the Journal of the Association for Nepal and Himalayan Studies. 1998;18(2), 7.

[12]. Fernandes H, D'souza PF and D'souza PM. Prevalence of transfusion transmitted infections in voluntary and replacement donors. Indian Journal of Hematology and blood transfusion. 2010;26(3), 89-91.

[13]. Yadav M, Verma N and Dhanda RS. Impact of sexually transmitted infections on women health. Health. 2013;5(08), 1216.

[14]. Prakash P, Bobati SS and Basavaraj V. Prevalence of Transfusion Transmissible Infections among Blood Donors in a Tertiary Care Hospital of Mysuru District-A Six Years Study. International Journal of tropical disease and health. 2016;3, 1-8.

[15]. Dobariya GH, Raja KA, Chirag A, Unagar CA, Pandya AN, and Patel JN. Prevalence and trends of transfusion transmitted infections among blood donors of blood bank attached to government hospital of South Gujarat, India. Int J Res Med Sci. 2016;4(9), 4123-4127.

[16]. Leena MS and Mohd S. Trend and prevalence of transfusion transmitted infections among blood donors in rural teaching institute, South India. Journal of Pathology of Nepal. 2012;2(3), 203-206.

[17]. Arshad A, Borhany M, Anwar N, Naseer I, Ansari R, Boota S and Shamsi T. Prevalence of transfusion transmissible infections in blood donors of Pakistan. BMC hematology. 2016;16(1), 27.

[18]. Datta S. An overview of molecular epidemiology of hepatitis B virus (HBV) in India. Virology Journal. 2008;5(1), 156.

[19]. Basavarju A, Kota R and Muttaraju P. Seroprevalence of HIV and HBsAg among blood donors of a tertiary care hospital: a cross-sectional study from Khammam, Andhra Pradesh. Medical Science. 2015;3(1):177-82.

[20]. Thomas E, Yoneda M and Schiff ER. Viral hepatitis: past and future of HBV and HDV. Cold Spring Harbor perspectives in medicine. 2015;5(2), a021345.

[21]. Alter MJ. Epidemiology of hepatitis C virus infection. World journal of gastroenterology: WJG. 2007;13(17), 2436.

[22]. Strathdee SA, Hallett TB, Bobrova N, Rhodes T, Booth R, Abdool R and Hankins CA. HIV and risk environment for injecting drug users: the past, present, and future. The Lancet. 2010; 376(9737), 268-284.

[23]. Silverman JG, Decker MR, Gupta J, Maheshwari A, Willis BM, Raj A. HIV prevalence and predictors of infection in sextrafficked Nepalese girls and women. Jama. 2007;298(5):536-42.

[24]. Gurubacharya DL and Gurubacharya VL. HIV prevalence among Nepalese migrant workers working in Nepal and Indian cities. Journal of the Nepal Medical Association. 2004;43(154).

[25]. Poudel KC, Okumura J, Sherchand JB, Jimba M, Murakami I, Wakai S. Mumbai disease in far western Nepal: HIV infection and syphilis among male migrant-returnees and nonmigrants. Trop Med Int Health. 2003;8(10):933-939.

[26]. National HIV Estimates, National Centre for AIDS and STD Control (NCASC). 2017.

[27]. Poudel KC, Nakahara S, Poudel-Tandukar K, Yasuoka J, Jimba M. Unsafe sexual behaviors among HIV-positive men in Kathmandu Valley, Nepal. AIDS Behav. 2009;13(6):1143-1150

[28]. Karki S, Tiwari BR, Ghimire P, Maharjan A and Rajkarnikar M. Seroprevalence of Specific Antibodies to Treponema pallidum in Blood Donors. Journal of Nepal Health Research Council. 2008;6(2), 98-101.

[29]. Raut MM, Joge US, Choudhary SG, Malkar VR and Ughade HM. Seroprevalence of transfusion transmitted infections among healthy blood donors at blood bank attached to a tertiary care hospital in Maharashtra state of India. International Journal of Health Sciences \& Research. 2012;2, 18-24.

[30]. Song Y, Bian Y, Petzold M and Ung COL. Prevalence and trend of major transfusiontransmissible infections among blood donors in Western China, 2005 through 2010. PloS one. 2014;9(4), e94528. 